José Luiz de Almeida Martins Costa - 100 anos de uma vida dedicada ao Direito ..... 205 Judith Martins-Costa

La «société sportive» dans quelques ordres juridiques étrangers Michael R. Will

A Autonomia da Vontade nos Contratos Internacionais - Direito Brasileiro e

Países do Mercosul: Considerações sobre a Necessidade de Alterações no

Direito Internacional Privado Obrigacional do Bloco. Nadia de Araujo

Mercosur - Una Introduction . Ricardo Luis Lorenzetti

× Colisão de Direitos Fundamentais e Realização de Direitos Fundamentais

no Estado de Direito Democrático Robert Alexy

\section{Informe Sobre La Responsabilidad Civil En El Proyecto Argentino De Codigo Civil De 1998(*)}

\author{
Atilia eAtubal EAltexini
}

Doctor en Derecho y Ciencias Sociales na Universidade de Buenos Aires

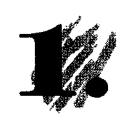

El 18 de diciembre de 1998, y luego de tres años y medio de trabajo, los miembros de la Comisión Honoraria que integramos con los profesores doctores Héctor Alegría, Jorge Horacio Alterini, María Josefa Méndez Costa, Julio César Rivera y Horacio Roitman, presentamos al Ministerio de Justicia argentino un Proyecto de Código Civil unificado con el Código de Comercio, de 2532 artículos (Su texto puede ser leído en http://www.alterini.org y en http:// www.lopezcabana.com, y descargado de http://snts1.jus.gov.ar/minis/Nuevo/ ProyectoCodigoCivil.htm/).

2. Dicho Proyecto de Código Civil de 1998 adoptó el criterio de unificación de las áreas contractual y extracontractual de responsabilidad civil, que están claramente diferenciadas en el Código Civil vigente. Su artículo 1107, que fue tomado de Aubry y
Rau, traza una frontera entre las órbitas contractual y extracontractual de responsabilidad, en cuanto establece que "los hechos o las omisiones en el cumplimiento de las obligaciones convencionales, no están comprendidos en los artículos de este Título (relativo a los hechos ilícitos), si no degeneran en delitos del Derecho criminal". De ello resultan varias diferencias de régimen, de las cuales las más importantes "son la extensión de la reparación y la concerniente al plazo de prescripción de las acciones" (XII Jornadas Nacionales de Derecho Civil, Bariloche, 1989).

A partir de 1987 tres proyectos de reformas propusieron llevar adelante esa unificación en Argentina. Así lo previó, en 1987, el Proyecto de Unificación de la Legislación Civil y Comercial, proveniente de la Cámara de Diputados de la Nación

(") Relación presentada en Roma el 12 de abril de 1999 en el Seminario "Derecho romano y unificación del Derecho. Experiencia europea y latinoamericana (con especial atención a la responsabilidad extracontractual"), realizado en la Università degli Studi di europea y latinoamericana (con especial atención a la responsabilidad extracontractual"), realizado en
Roma Tor Vergata con el cual se abrió el Corso di Perfezionamiento e di Magister del corriente año. 
(año 1987), que fue preparado por una Comisión Honoraria que integraron los profesores Héctor Alegría, Jorge Horacio Alterini, Miguel Carlos Araya, Francisco A. de la Vega, Horacio P. Fargosi, Sergio Le Pera, Ana Isabel Piaggi y el que habla; fue sancionado por el Parlamento, tuvo registro con el número 24.032, pero el Poder Ejecutivo la vetó íntegramente mediante el decreto 2.719/91. Posteriormente, la denominada Comisión Federal de la Cámara de Diputados de la Nación elaboró, a su vez, otro proyecto de unificación, que fue sancionado el 3 de noviembre de 1993 y pasó en revisión al Senado; la Comisión Honoraria redactora fue integrada por los doctores Héctor Alegría, Jorge Horacio Alterini, Miguel Carlos Araya, María Artieda de Duré, Alberto Mario Azpeitía, Enrique C. Banchio, Alberto J. Bueres, Osvaldo Camisar, Marcos M. Córdoba Rafael Manóvil, Luis Moisset de Espanés, Jorge Mosset Iturraspe, Juan Carlos Palmero, Ana Isabel Piaggi, Efraín Hugo Richard, Néstor E. Solari, Félix Alberto Trigo Represas y Ernesto C. Wayar. Un tercer proyecto, con idéntica finalidad, fue preparado a instancias del Poder Ejecutivo Nacional por una Comisión creada por decreto del Poder Ejecutivo Nacional 468/ 92, cuyo texto fue remitido al Senado de la Nación, y publicado en el Diario de Asuntos Entrados del 13 de agosto de 1993; la Comisión redactora estuvo compuesta por los doctores Augusto C. Belluscio, Salvador Darío Bergel, Aída R. Kemelmajer de Carlucci, Sergio Le Pera, Julio César Rivera, Federico Videla Escalada y Eduardo A. Zannoni.

Como se recuerda en los Fundamentos del Proyecto de Código Civil de 1998, no obstante la literalidad textual del mencionado artículo 1107, la frontera que traza fue debilitada por varios estatutos legales. La índole contractual o extracontractual de la responsabilidad es indiferente en los casos de daños resultantes del riesgo minero (artículo 58 del Código de Minería) o de la explotación de una instalación nuclear (Convención de Viena de 1963 sobre Daños Derivados del Uso Pacífico de la Energía Nuclear - ley 17.048, artículo IV). La responsabilidad para el caso de ruina de obra que impone el artículo 1646 del Código Civil (según ley 17.711) rige tanto para el comitente cuanto para los terceros. El carácter contractual propio de la relación laboral no obstó en su momento a la aplicación del artículo 1113 del Código Civil (Cám. Nac. del Trabajo en pleno, 26.10.71, "Alegre c/ Manufactura Algodonera Argentina"). El artículo 1º de la ley 23.592, al prever la reparación del daño moral y material ocasionado por un acto discriminatorio, no dispensa un tratamiento distinto según se origine dentro o fuera del área contractual. En el régimen estatutario del consumidor la legitimación pasiva es idéntica, sea que se trate de daños contractuales o extracontractuales (artículo 40 de la ley 24.240 de defensa del consumidor, según ley 14.999). Las citadas XII Jornadas Nacionales de Derecho Civil consideraron que "existe unidad sistemática en materia de responsabilidad civil, a partir del dato de concebir al daño como el centro de gravedad del sistema".

Sin embargo, las principales diferencias que subsisten entre los regímenes contractual y extracontractual de responsabilidad (diversa extensión de la responsabilidad, distintos plazos de prescripción), tienen significativa incidencia en el Derecho de daños, y justifican el sostenido reclamo de la doctrina por la unificación de ambos sistemas. En ese sentido, las Jornadas de Responsabilidad por Daños en Homenaje al Doctor Jorge Bustamante Alsina (Buenos Aires, 1990) recomendaron establecer una única regla de atribución de daños con base en la idea de relación de causalidad adecuada, y unificar los plazos de prescripción liberatoria.

3. Ese es uno de los ejes del Proyecto de 1998, cuyo artículo 1581 dispone que las normas atinentes a la responsabilidad civil "son aplicables cualquiera que sea la fuente del deber jurídico de cumplir o de reparar el daño".

Por lo tanto, unifica la extensión de la responsabilidad, con respecto a lo cual el artículo 1609 adopta la teoría de la causalidad adecuada, en estos términos: "La responsabilidad abarca las consecuencias que se hallan en relación de causalidad adecuada con el hecho generador. Quedan comprendidas en ellas las consecuencias inmediatas y las consecuencias mediatas previstas o previsibles; y están excluidas las consecuencias casuales".

Unifica también la regulación de la prescripción liberatoria pues, conforme al artículo 2501, está sujeta al plazo de cuatro años; en el Código vigente rige el plazo de diez años para la responsabilidad contractual (artículo 4023), y el de dos años para la responsabilidad extracontractual (artículo 4037). Ello no impide que el Proyecto prevea plazos especiales de dos años para "la acción para reclamar indemnización de daños por la circulación terrestre de vehículos de toda especie", para "la acción de Derecho común para reclamar indemnización de daños derivados de accidentes y enfermedades del trabajo", y para "todas las acciones derivadas del contrato de transporte terrestre" (artículo 2502, incisos b, c y d). La aplicación de un plazo de prescripción más breve que el ordinario para los daños derivados de la circulación terrestre de vehículos fue inspirada por el artículo 2947 del Código Civil italiano. El plazo bienal para los infortunios laborales es el fijado por la legislación especial (artículo 56, ley 10744 [t.o. decreto 390/76] y artículo 24, ley 24.557). En materia de transporte terrestre, actualmente la situación es caótica: si un pasajero es dañado cuando viaja en un vehículo en el transporte interno, rige el plazo de un año (artículo 855 del Código de Comercio, según ley 22.076), pero si el damnificado por el vehículo es un peatón se aplica el plazo de dos años (artículo 4037, Código Civil); para mayor confusión, en la Provincia de Buenos Aires -que es la jurisdicción judicial que cuenta con mayor número de habitantes- una jurisprudencia pretoriana extiende a dos años el plazo de que dispone el pasajero (Suprema Corte de Buenos Aires, L.L. 1986-D-659; 1986-E. 69).

4. Otro eje del Proyecto de 1998 es la prevención del daño, a la que se tiende mediante tres mecanismos: la consagración del deber de evitar el daño, la asignación de virtualidades a las medidas técnicas tendientes a evitarlo, y la tutela inhibitoria. 
En los Fundamentos del Proyecto se recuerda que el Código Civil no aceptó la cautio damni infecti (artículo 1132), no obstante lo cual la ley de reformas 17.711 del año 1968 dio lugar a la denuncia de daño temido, autorizando la traba de medidas cautelares en la eventualidad de que de una cosa deriven daños (agregado al artículo 2499) o molestias (nuevo artículo 2618), las cuales son aplicaciones de la teoría de la prevención del daño. Esta es protagonista principal del pensamiento moderno, que procura una solución ex ante en vez de una respuesta ex post como la que tradicionalmente se daba mediante la indemnización de un perjuicio ya producido de no ser así, «ello importaría tanto como crear el derecho de perjudicar» (Aguiar) Los Fundamentos agregan: "La prevención tiene un sentido profundamente humanista pero, a la vez, es económicamente eficiente. Porque la evitación de daños no sólo es valiosa desde la perspectiva ética, sino también desde el puro punto de vista macroeconómico: por ejemplo, cuando resultan daños personales de la circulación de vehículos, los costos sociales aumentan por la mayor utilización de hospitales públicos, y por la mayor actividad de los servicios de policía y de administración de justicia".

La Constitución Nacional, tras la reforma del año 1994, concede la acción de amparo cuando son amenazados derechos y garantías reconocidos por ella (artículo 43) $y$, asimismo, insta a la "prevención" de conflictos relativos a los servicios públicos (artículo 42 in fine).

a) Con respecto al primero de los mencionados mecanismos de prevención. la consagración explícita del deber de evitar el daño-, el artículo 1585 del Proyecto establece que "Toda persona tiene el deber, en cuanto dependa de ella: a) De evitar causar un daño no justificado. b) De adoptar, de buena fe y conforme a las circunstancias, las medidas razonables para evitar que se produzca un daño, o disminuir su magnitud. Si tales medidas evitaron o disminuyeron la magnitud de un daño, del cual un tercero habría sido responsable, tiene derecho a que éste le reembolse el valor de los gastos en que ha incurrido para adoptarlas, conforme a las reglas del enriquecimiento sin causa. c) De no agravar el daño, si ya se ha producido".

Correlativamente, el artículo 1587 dispone: "El tribunal tiene atribuciones para aplicar una multa civil a quien actúa con grave indiferencia respecto de los derechos ajenos o de los intereses de incidencia colectiva. Su monto se fija tomando en consideración las circunstancias del caso, en especial los beneficios que aquél obtuvo o pudo haber obtenido con su conducta, y tiene el destino que le asigne el tribunal por resolución fundada".

En Europa se ha desarrollado la idea de pena privada, que Hugueney desarrolló tempranamente en Francia ("Lidée de peine privée en Droit contemporain", Dijon, 1904), y que en la actualidad está firmemente establecida (por todos, Viney, G., "Les obligations. La responsabilité: effets", Paris, 1988, № 4, pág. 5). La regulación propuesta por el Proyecto de 1998 está emparentada con dicha idea de pena privada y, en particular, con la de daños punitivos -o, mejor dicho, condenaciones punitivas-, de los que trata el $\S 908$, ap. 1 , del Restatement of Torts 2 nd., según el cual sirven para "penar a una persona por su conducta ofensiva, y para disuadir a ella, y a otros como ella, de obrar una conducta similar en el futuro", por lo que cumplen funciones de prevención especial y de prevención general. El apartado 2 del mismo $\S 908$ del Restatement especifica que los "daños punitivos" pueden ser aplicados "por una conducta ofensiva, en razón de los motivos perversos del demandado, o de su indiferencia respecto de los derechos ajenos", tomando en consideración "el carácter del acto del demandado, la naturaleza y la extensión del perjuicio que el actor causó o intentó causar, y la fortuna del demandado". En Inglaterra -no obstante que los punitive damages fueron restringidos en 1964 por la sentencia de la Cámara de los Lores en la causa "Rookes v. Barnard" [A.C. 1129]- son otorgados si el condenado obtuvo beneficios superiores al monto de la indemnización. En Francia, la sentencia del 13 de febrero de 1991 dictada en la causa "Belmondo" -según el criterio del primer Abogado General Lindon- incriminó a quienes "se especializan en la revelación de secretos de alcoba [pues] saben antes de publicar una indiscreción o una fotografía que les valdrá un proceso y una condena, consultan con su abogado sobre el monto probable de esta condena, y, después de haber comparado esta evaluación con la cifra de sus negocios, toman alegremente la responsabilidad de exponerse a los rayos por demás mojados de la Justicia" (J.C.P., 71, II, 16774).
Desde otra perspectiva confluyente, el artículo 115 del Proyecto dispone que "no es exigible el cumplimiento del contrato que tiene por objeto la realización de actos peligrosos para la vida o la integridad de una persona, salvo que correspondan a su actividad habitual y que se adopten las medidas de prevención y seguridad adecuadas a las circunstancias".

b) Una segunda vía de acción de la prevención del daño es instar a la adopción de medidas técnicas tendientes a evitar el daño. Conforme al Proyecto de Código Civil de 1998, si el sindicado como responsable las adoptó, se libera cuando el daño proviene de cosa sin riesgo propio; y tiene el derecho de prevalerse de ciertos topes cuantitativos a la indemnización.

El artículo 1667 del Proyecto dispone que "el guardián es responsable por el daño causado por una cosa que carece de riesgo", pero aquél "se libera, total o parcialmente, si prueba haber actuado con diligencia, a cuyo fin debe haber adoptado las medidas de prevención razonablemente adecuadas".

Conforme al artículo 1634, como veremos luego, la limitación cuantitativa de responsabilidad objetiva no es invocable por quien "no adoptó las medidas de prevención razonablemente adecuadas".

También veremos que el artículo 1669 libera de la responsabilidad resultante de la obligación de seguridad de medios a quien adoptó "las medidas de prevención razonablemente adecuadas".

c) La tercera vía de acción es la tutela inhibitoria, que tiende a prevenir la realización o la reiteración de un daño, es 
decir, actúa aunque éste no se haya producido y, en todo caso, intenta evitar su repetición. Como se sabe, a diferencia de la tutela cautelar, la tutela inhibitoria no depende de una acción principal, y puede ser positiva o mandatoria, cuando el tribunal impone un hacer; y negativa o prohibitiva, cuando impone una abstención. Seguramente, para aplicarla es preciso tener en consideración el agudo criterio de Larenz acerca de la "justa medida", con la cual se logra -eficientemente- el adecuado equilibrio de intereses contrapuestos en la línea del menor perjuicio.

El artículo 1586 del Proyecto de Código Civil de 1998 prevé al respecto que "el tribunal tiene atribuciones para disponer, conforme a las circunstancias, medidas tendientes a evitar la producción de daño futuro". La doctrina argentina acepta ese criterio (por todos, Zavala de González, M., "La tutela inhibitoria contra daños", en Revista de Responsabilidad Civil y Seguros, año I, № 1, enero-febrero de 1999, pág. 1), y los jueces la han dispuesto incluso de oficio, por ejemplo, en el caso en que una niña de trece años cayó en un depósito artificial de agua producido por excavaciones en la vía pública y murió por asfixia, ordenando que la municipalidad con función preventiva de daños a otras personas-colocara una cerca protectora en torno a las excavaciones inundadas, así como carteles indicadores de peligro, y que mantuviera un servicio permanente de vigilancia en el lugar durante las horas diurnas (Cámara Federal de la Plata, Sala III, L.L., 1989-C-117).
5. Otro eje del Proyecto de Código Civil de 1998 es la dilución del requisito de antijuridicidad, con un criterio ya propiciado por el Proyecto de Código Único de 1987. Es útil recordar lo que expresan al respecto sus Fundamentos: "La responsabilidad civil está emplazada en un área móvil. Los viejos odres del Código Civil resultaron insuficientes para contener las soluciones apropiadas a los tiempos cambiantes, tanto que en la Era Industrial, seguramente, la respuesta más singular resultó de la legislación laboral. Cuando se entró en los albores de la Era Tecnológica fueron repensadas ideas generalmente tenidas por válidas, y se procuró dar soluciones adecuadas a los nuevos requerimientos, muchas veces mediante una relectura de los antiguos textos legales. En Argentina, como en el Mundo, el concepto de responsabilidad civil evolucionó de una deuda de responsabilidad a un crédito de indemnización (LambertFaivre); hoy importa la injusticia del daño antes bien que la injusticia de la conducta generadora (López Olaciregui), porque 'el Derecho contemporáneo mira del lado de la víctima y no del lado del autor' (Ripert) El Proyecto pretende adecuarse al criterio de que la modificación de perspectiva 'sólo será válida y valiosa en la medida en que tenga al Hombre como núcleo y pivote; en que lo sirva y sea útil para su realización' (Messina de Estrella Gutiérrez). En un importante fallo del año 1986 (CSJN in re 'Santa Coloma, Luis F. y otros c/ Empresa Ferrocarriles Argentinos') la Corte Suprema de Justicia de la Nación dio impulso a las nuevas ideas al señalar dos pautas de significación fundamental: que el principio alterum non laedere tiene raíz constitucional, y que las soluciones jurídicas deben adecuar al sentido de justicia de la sociedad. En cuanto a la primera expresión, se colige fácilmente que, cuando menos en la literalidad, es aun más amplia que la conclusión de la famosa sentencia del Consejo Constitucional francés del 22 de octubre de 1982 (D.S., 1983, 189; G.P., 1983, I, 60), pues no incluye el requisito de la culpa (faute) como antecedente de la indemnización. Y en cuanto a la segunda, que el hombre contemporáneo tiene la expectativa de que cualquier daño le sea resarcido, puesto que dejó de inclinarse con resignación 'ante el azar nefasto' (Mazeaud). En este sentido, las XII Jornadas Nacionales de Derecho Civil (Bariloche, 1989) declararon, por unanimidad, que uno de los 'mecanismos desmasificadores' es 'la moderna concepción del derecho de daños, que centra su óptica en la víctima' ".

En Argentina, la sustitución del concepto de antijuridicidad plasmado en el vigente artículo 1066 del Código Civil resulta de todos los últimos proyectos de reformas. El Proyecto de Código Unico de 1987 propició la derogación de ese texto del Código Civil. El Proyecto de la Comisión Federal de la Cámara de Diputados de la Nación de 1993, lo sustituyó por este otro: "Todo acto positivo o negativo que causa un daño es antijurídico si no se encuentra justificado". El Proyecto del Poder Ejecutivo Nacional de 1993 previó, para un nuevo artículo 1549, la siguiente versión: "La violación del deber de no dañar a otro genera la obligación de reparar el daño causado, conforme a las disposiciones de este Código"; y, para el artículo 1550, esta otra: "Salvo disposición legal en contrario, no son indemnizables los daños causados en el ejercicio regular de un derecho o facultad".

La antijuridicidad, que supone una conducta que, en sí misma, es ilícita, se desvanece como presupuesto de esa responsabilidad no bien se acepta que es reparable el daño sufrido injustamente, sin que sea menester que se trate de un daño inferido ilícitamente. El tema, pues, se traslada a la teoría de las causas de justificación. La conducta que causa un daño, o tiene aptitud para causarlo (artículo 1067, Cód. Civil), aunque no sea antijurídica, genera responsabilidad cuando no está justificada: por ejemplo, porque no implica el ejercicio regular de un derecho (artículo 1071, Cód. Civil y doc. artículo 34, inciso 4ํㅜㄹ. Cód. Penal), o legítima defensa (doc. artículo 34, inciso 6o, Cód. Penal).

Ello significa que la responsabilidad es controlada principalmente mediante la idea del ejercicio regular del derecho de obrar. Sólo se atribuye al causante el daño injusto, y únicamente se considera injusto al que es causado sin derecho. La cuestión se ve claramente en materia de competencia comercial: es obvio que la instalación de un nuevo competidor en determinado mercado perjudica a quienes ya estaban operando en ese mercado, porque el recién llegado absorbe a algunos clientes que eran de ellos; pero, mientras el nuevo competidor actúe regularmente, ajustándose a las reglas de la competencia leal, nadie puede reclamarle indemnización alguna.

En ese orden de ideas el artículo 1588 del Proyecto de Código Civil de 1588 
establece: "Debe ser reparado el daño causado a un derecho, o a un interés que no sea contrario a la ley, si no está justificado". El artículo 1589 prevé: "El daño está justificado: a) Si es causado en el ejercicio regular de un derecho o de una facultad, salvo en el caso del artículo 1676 [responsabilidad del Estado por actos lícitos]. b) Si es causado en defensa propia, por un medio racionalmente proporcionado, frente a una agresión actual, injusta y no provocada. c) Si es causado para conjurar un mal actual o temido, injusto y no provocado, y de otro modo inevitable, que amenaza al agente o a un tercero. Quien sufre el daño tiene derecho a ser compensado equitativamente por el beneficiado. d) En el ámbito de las relaciones de familia, si la admisión de una acción reparatoria puede poner en peligro los intereses generales respecto de la persistencia y de la estabilidad de la institución familiar, de la solidaridad entre sus miembros y, en su caso, de la piedad filial. e) En el caso de afectar intereses de incidencia colectiva, si corresponde considerarlo socialmente tolerable en razón del interés general. f) Si lo dispone la ley".

6. La atribución objetiva de responsabilidad está prevista con amplitud en el Proyecto. Pero en los Fundamentos se considera "a la culpa la 'norma de clausura' del sistema (Schipani)", por lo cual el artículo 1602 prevé: "La responsabilidad es atribuida en los casos y conforme a las circunstancias en que lo dispone la ley o lo estipulan las partes.A falta de norma legal, o de estipulación de partes, el factor de atribución es la culpa".
Conforme al artículo 1662, “se considera cosa riesgosa a la que tiene en sí misma aptitud para causar daños frecuentes o graves, por sus propias calidades, o por las circunstancias en que es utilizada", comprendiendo a "los residuos industriales actual o potencialmente peligrosos, y los radiactivos" (artículo 1663). Conforme al artículo 1664, "El guardián es responsable del daño causado por la cosa riesgosa. Se considera guardián a quien ejerce, por sí o por terceros, un poder de hecho sobre la cosa, o se sirve de ella. El dueño responde concurrentemente si se ha desprendido voluntariamente de la guarda y la cosa es usada conforme a su voluntad expresa o tácita" (artículo 1664). A su vez, el artículo 1665 establece: "Quien realiza una actividad especialmente peligrosa, se sirve u obtiene provecho de ella, por sí o por terceros, es responsable del daño causado por esa actividad. Se considera actividad especialmente peligrosa a la que, por su naturaleza, o por las sustancias, instrumentos o energía empleados, o por las circunstancias en las que es llevada a cabo, tiene aptitud para causar daños frecuentes o graves".

La eximición de responsabilidad está sujeta a un sistema estricto, pues el artículo 1666 prevé que "sólo se libera de ella, total o parcialmente, si prueba que la causa del daño es la culpa del damnificado"; y que "no son invocables como eximentes la autorización administrativa para el uso de la cosa o la realización de la actividad, el cumplimiento de las técnicas de prevención, el caso fortuito, el hecho de un tercero, ni cualquier otra causa ajena".
7. Para los casos de cosas con riesgo que incluyen a los vehículos [artículo 1684], a los animales [artículo 1670], a ciertos daños que afectan a intereses de incidencia colectiva [artículo 1622], al impacto del cuerpo humano [artículo 1671], al tomador del leasing [artículo 1169]- o de actividades especialmente peligrosas, así como para el transporte terrestre (artículo 1206), rige la limitación cuantitativa de la responsabilidad.

La he sostenido desde hace treinta años, y he escrito especialmente sobre ella (Alterini, A. A., "La limitación cuantitativa de la responsabilidad", Buenos Aires, 1997). Los argumentos justificantes están expuestos con suficiente amplitud en los Fundamentos del Proyecto:

"No obstante que se predica enfáticamente el denominado principio de reparación integral, en la realidad de las cosas sólo se trata de la reparación plena. 'La reparación integral no significa que todo lo que la víctima pretende merezca reparación' (Larroumet), pues 'el principio no expresa en realidad más que un deseo', y las más de las veces la indemnización 'no aporta más que una cierta compensación de daño' (Tunc). La responsabilidad civil tiene por finalidad procurar volver al status quo ante del daño, esto es, 'la reposición de las cosas a su estado anterior' (artículo 1083, Código Civil, según ley 17.711), pero sólo se trata de la reposición del damnificado 'a una situación tan próxima como sea posible a aquella en la que habría estado si el hecho dañoso no se hubiera producido (Resolución 7 del Comité de Ministros de Consejo de Europa del 14 de marzo de 1975 Anexo, artículo 1).
Cuando algunos objetan la limitación cuantitativa de la responsabilidad suelen entender la reparación integral en una de sus acepciones, la de reparación 'total', esto es, de todo el daño, lo cual no resulta posible: lo integral, en el caso, es la reparación en otra de sus acepciones, la de reparación 'global', vale decir, la que 'toma en conjunto' a los daños que el sistema admite como reparables. Se trata de la plenitud propia de cada uno de los ordenamientos jurídicos singulares, porque los sistemas tienen sus reglas específicas para asignar responsabilidad a uno o a otro sujeto; para excluir el derecho a la reparación, en el todo o con relación a ciertos daños; para negar legitimación a algunas víctimas; para modular los factores de atribución y las causas de irresponsabilidad; para morigerar la reparación, etcétera. Los ordenamientos jurídicos, sin excepción alguna, limitan cualitativamente la indemnización - sobre todo en función de la causalidad a la que consideran jurídicamente relevante -, las disposiciones pertinentes están en ellos desde siempre, las hemos aceptado -o, por lo menos, tolerado -, pero la cuestión se agita cuando se sugiere limitarla también cuantitativamente.

Los límites cuantitativos de la indemnización no son extraños al sistema. El Código Civil trae algunas hipótesis nítidas en materia de obligaciones: cuando se estipula una cláusula penal, porque 'el acreedor no tendrá derecho a otra indemnización, aunque pruebe que la pena no es indemnización suficiente' (artículo $655)$; en las obligaciones dinerarias, en las cuales la responsabilidad del deudor consiste en el pago de 'los intereses' 
(artículo 621). En materia de hospedaje, el posadero sólo responde del valor de los objetos corrientes introducidos por el pasajero, pues si éste 'trajese consigo objetos de gran valor, de los que regularmente no llevan consigo los viajeros, debe hacerlo saber al posadero, y aun mostrárselos si éste lo exige, y de no hacerlo así, el posadero no es responsable de su pérdida' (artículo 2235, Código Civil). Conforme al Código de Comercio, el transportador terrestre sólo responde por el valor declarado del 'dinero, alhajas o efectos de gran valor y documentos de crédito' (artículo 173); y la indemnización es 'tasada por peritos según el valor que tendrían los efectos en el lugar y tiempo de la entrega' (artículo 179), lo cual excluye la reparabilidad de otros daños. Los límites cuantitativos también resultan de diversas leyes especiales. En materia de infortunios laborales, a partir de la ley 9.688 (del año 1915) se estableció un tope indemnizatorio que, en la actualidad, es de $\$ 55.000$ para el caso de incapacidad o muerte (ley 24.557, artículos 14, inciso 2; 15, inciso 2; y 18, inciso 2). La Convención de Viena sobre Responsabilidad Civil por Daños Nucleares de 1963 (ratificada por ley 17.048) limita la responsabilidad a '5.000.000 de dólares de los Estados Unidos por cada accidente nuclear' (artículo V, inciso 1). En materia de navegación aérea en el territorio nacional, el Código Aeronáutico (ley 17.285) dispone que la responsabilidad por daños sufridos por el pasajero queda limitada a 1.000 argentinos oro (artículo 144); para los daños causados a terceros en superficie, 'la indemnización en caso de muerte o lesiones no excederá de 2.000 argentinos oro' (artículo 160). Para igual hipótesis de daños sufridos por el pasajero, el tope cuantitativo en la navegación aérea internacional, conforme al Convenio de Varsovia 1929 según Protocolo de la Haya de 1955 (ratificado por ley 17.386), es de 250.000 francos oro (artículo 22). Para el transporte interno de mercancías y equipajes, el límite cuantitativo es de 2 argentinos oro por kilogramo de peso bruto, salvo que el expedidor declare el valor 'mediante el pago de una tasa suplementaria eventual'; y de 40 argentinos oro 'en lo que respecta a los objetos cuya guarda conserva el pasajero' (artículo 145, Código Aeronáutico); para el transporte internacional, ese límite es de 250 francos oro (artículo 22, 2 $2^{\mathrm{a}}$ parte, Convenio de Varsovia). La Ley 20.064 de Navegación por agua fija un máximo de 1.500 pesos argentinos oro 'por daños resultantes de muerte o lesiones corporales de un pasajero' (artículo 331). La navegación marítima internacional está regida por el Convenio de Atenas de 1974, con su correspondiente protocolo (ratificado por ley 22.718): la responsabilidad por muerte o lesiones corporales del pasajero queda limitada a 700.000 francos oro (artículo 7). La ley 20.064 fija el límite para las pérdidas o daños que sufran las mercaderías en 400 pesos argentinos oro por cada bulto o pieza o, en su caso, por cada unidad de flete, salvo que 'el cargador haya declarado, antes del embarque, la naturaleza y valor de la mercadería'. Con relación al equipaje del pasajero, los máximos son de 150 pesos argentinos oro para el guardado en bodega, y de 100 pesos argentinos oro para el llevado en cabina, así como de 350 pesos argentinos oro para los vehículos y el equipaje ubicado dentro de ellos (artículo 337). El Convenio de Atenas de 1974 establece estos límites: 12.500 francos oro para el 'equipaje de camarote'; 18.000 francos oro para el equipaje en bodega; 50.000 francos para vehículos, incluyendo al equipaje que lleven (artículo 8). En el Mercosur, el Acuerdo de Transporte Multimodal Internacional (Decisión del Consejo del Mercado Común 15/94) se aplica al 'porte de mercaderías por dos modos diferentes de transporte, por lo menos' (artículo 1, inciso a). De él resulta una limitación cuantitativa: 'salvo que la naturaleza y el valor de las mercaderías hayan sido declarados por el expedidor antes que el operador de transporte multimodal los haya tomado bajo su custodia [...], el operador de transporte multimodal no será ni podrá ser tenido por responsable en ningún caso de la pérdida o el daño de las mercaderías por una suma que exceda del límite de responsabilidad que establezca cada Estado Parte' (artículo 13) salvo que el evento 'se haya producido en una fase determinada del transporte multimodal respecto de la cual un convenio internacional aplicable o una ley imperativa en ese país establecieren otro límite de responsabilidad' (artículo 15). La responsabilidad por el 'retraso en la entrega' o por 'cualquier pérdida o daños indirectos distintos de la pérdida o el daño de las mercaderías', tiene como límite el 'equivalente al flete' (artículo 16). Conforme al Anexo I de ese Acuerdo, Argentina determina el límite 'de 400 pesos argentinos oro por kilogramo del volumen o pieza afectada, o de 10 pesos argentinos oro por kilo del volumen o piezas afectadas, si este valor fuera superior'. La ley 24.441 dispone que, en el fideicomiso, la responsabilidad objetiva del fiduciario se limita al valor de la cosa fideicomitida si 'no pudo razonablemente haberse asegurado' (artículo 14). Por lo cual, si no pudo tomar un seguro, su responsabilidad es limitada al valor de la cosa; pero si, pudiendo haberlo hecho, no lo hizo, esa limitación no rige.

Asimismo, dichos topes indemnizatorios son aceptados por prestigiosa doctrina internacional y son corrientes en el Derecho comparado para los casos de responsabilidad objetiva (Portugal, Código Civil de 1967; Québec, Holanda, Código Civil de 1992; España, ley 30/95; Alemania, Estados Unidos de América, Dinamarca, México), son frecuentes en los accidentes de tránsito, y aun se dan para la responsabilidad médica y farmacéutica (Suecia) y para la farmacéutica (Noruega). La ley danesa de 1984 abarca en los topes a las indemnizaciones del Derecho común, aunque no deriven de responsabilidad objetiva.

La responsabilidad objetiva derivó de la 'dificultad de la reconstrucción de la acción humana' y de 'la existencia de daños anónimos y estadísticamente previsibles' (Rodotà). Y la limitación cuantitativa de la responsabilidad en esa área ha sido justificada como contrapartida del deber de resarcir el daño que se impone a quien lo ha causado sin culpa: la atribución objetiva favorece a la víctima, pues facilita la actuación de su derecho pero, a cambio, se le pone un techo a su indemnización (Acuña Anzorena, con apoyo en Demogue 
y Charmont; Deveali; Larroumet), a fin de que 'las cargas no pesen íntegramente sobre ninguno de los dos sujetos' (Moisset de Espanés).

Por otra parte, la limitación cuantitativa de la responsabilidad no afecta en su esencia al derecho de propiedad. El derecho de propiedad del damnificado (su crédito indemnizatorio) es, en definitiva, el que le asigna la ley. Los topes indemnizatorios son una cuestión atinente a la política jurídica (Roujou de Boubée), porque no se discute que 'el Derecho puede limitar o restringir el contenido normal del daño', y 'este límite puede consistir en una cifra dineraria fijada por la ley' (de Cupis), aplicando un criterio mediante el cual 'la 'lotería judicial' es sustituida por la intervención legislativa' (Alpa). Tampoco afecta el derecho de la persona pues, cuando se lo lesiona injustamente, siempre es reparado de manera necesariamente incompleta y forzosamente distorsionada: el equilibrio entre el dolor y el dinero, entre la frustración del goce de bienes de la vida y el dinero, entre la pérdida de un brazo y el dinero, es sólo una estimación racional -que no condice con el ser de las cosas-, determinada por la imposibilidad de procurar el restablecimiento al status quo ante al daño por otros medios, como enseñó magistralmente Ihering. La manera idónea de proteger el derecho de la persona es evitar a toda costa que sea lesionado, lo cual constituye materia específica de la prevención, ya aludida; los límites cuantitativos, en definitiva, sólo vienen a agregarse a otros que ya existen en el sistema, que son propios de su estructura, y con los cuales convivimos más o menos en paz. Ellos tampoco ponen en compromiso la igualdad, pues las categorías que actualmente abarcan no resultan haber sido establecidas con efectos discriminatorios. $\mathrm{Ni}$ esquivan a la jurisdicción judicial, por lo pronto, porque los jueces deben aplicar las leyes (artículo 15, Código Civil), y es competencia del legislador regular los alcances de la responsabilidad (artículo 75, inciso 12, Constitución Nacional), como lo ha hecho hasta ahora, tanto en cuanto a sus límites cualitativos como en cuanto a sus límites cuantitativos; y, si bien el derecho a la indemnización emana de la garantía del artículo 19 de la Constitución Nacional -y, seguramente, del artículo 33-, los poderes reglamentarios del legislador sólo tienen como límite la razonabilidad y la adecuación a un cierto sentido de justicia (artículo 28, Constitución Nacional). Por otra parte, las indemnizaciones están sujetas a la autonomía de la voluntad pues, en general, pueden ser convenidas por los interesados, transadas (artículo 842, Código Civil) y sometidas a arbitraje (artículo 763, Código Procesal) o a juicio de peritos (artículo 57, ley 17.418), y están alcanzadas por la mediación obligatoria (artículos 1 y 2, ley 24.573).

Es cierto que, si la ley tarifa el daño mediante baremos fijos, la tarea judicial de alguna manera se desluce. Pero no lo es menos que los regímenes que los establecen dejan márgenes para aplicarlos al caso conforme a lo que sea justo. Además, como no se trata de la reparación automática del daño por un monto prefijado, el tribunal tiene que resolver antes que todo si el demandante está legitimado para reclamar la indemnización de los daños que pretende y si el demandado es responsable o no lo es, establecer después la extensión de su deber de reparar conforme a las reglas de la causalidad adecuada y, recién al final, aplicar el límite cuantitativo. Asimismo, como el derecho indemnizatorio de todos los damnificados debe ser satisfecho con un monto máximo, también incumbe al tribunal precisar en qué proporciones concurren unos y otros sobre ese monto.

Disminuir la litigiosidad es un desiderátum. Pero también lo es, y fundamentalmente, que existan los mecanismos legales necesarios para que las víctimas cobren, rápida y efectivamente, una indemnización razonable y predictible: 'las partes debieran poder predecir con cierta medida de exactitud el monto que probablemente será sentenciado en un caso particular, para que los casos puedan ser arreglados pacíficamente y no llevados al tribunal, lo cual satisface al bien público' (Lord Denning, en 'Ward v. James' [1966] 1 QB 273 299). Al igual que los contratos, los acuerdos privados extrajudiciales referidos a la indemnización tienen 'una condición necesaria para el éxito, que es llegar a un monto, con el cual ambas partes concluirían que el acuerdo incrementaría su bienestar' $y$, 'por lo tanto, las negociaciones de arreglo fracasarán, y sobrevendrá el litigio, sólo si el mínimo monto que el acreedor está dispuesto a aceptar para transar su reclamo, es mayor que el máximo monto que el deudor está dispuesto a pagar para satisfacer ese reclamo' (Posner). 'Es preciso, antes que todo, que los riesgos sean atribuidos claramente, a fin de que ninguna de las partes de que se trata tenga sorpresas'
(Tunc). Cuando una de las variables del conflicto -el monto máximo del reclamo del damnificado-resulta del tope cuantitativo, sólo queda en discusión si el responsable se aviene a pagarlo, y ello, indudablemente, hace más fácil que se llegue al acuerdo extrajudicial.

En síntesis, los topes indemnizatorios, articulados con el seguro y con arbitrios de pronto pago, no generan, por sí, una litigiosidad mayor. Por lo contrario, la disminuyen. Y garantizan a la víctima que un ente solvente (la aseguradora) cubrirá las eventuales defecciones del responsable, y que el monto indemnizatorio estará prontamente a su disposición".

El artículo 1634 del Proyecto de Código Civil de 1998 establece: "En los casos previstos por los artículos 1662 [cosa con riesgo y supuestos asimilados], 1663 [residuos industriales y radiactivos] y 1665 [actividad especialmente peligrosa], la reparación del daño queda limitada a la cantidad de trescientos mil (300.000) pesos [U\$s 300.000] por cada damnificado directo, que se reduce proporcionalmente si hay liberación parcial conforme al artículo 1666. El responsable no tiene derecho a prevalerse de la limitación: a) Si actuó sin diligencia y, en especial, si no adoptó las medidas de prevención razonablemente adecuadas. b) Si razonablemente debió haber asegurado ese riesgo y no lo hizo. c) Si tomó un seguro y la aseguradora no pone a disposición del damnificado la indemnización que corresponde en el tiempo oportuno para la liquidación del siniestro conforme a la legislación de seguros, a menos que, interpelado el 
responsable, ponga a disposición de aquél esa indemnización dentro de los treinta (30) días. d) Si se convino una indemnización mayor. Si el damnificado directo sufre gran discapacidad el tribunal puede aumentar el máximo indemnizatorio hasta el triple. Las disposiciones de este artículo dejan a salvo lo establecido por la legislación especial".

El Proyecto también obliga al dador del leasing a tomar un seguro y, si no lo hace, responde plenamente (artículo 1169).

Propone también modificar la ley de seguros, ajustando el texto del artículo 118 de la ley 17.418 para hacerlo eficaz: "Acción directa del asegurado. En los seguros por responsabilidad civil el damnificado tiene acción directa contra el asegurador [...]. Epoca del pago. El artículo 49 se aplica a los seguros por responsabilidad civil. Si el asegurador no pone la indemnización a disposición del damnificado en las oportunidades allí establecidas, queda obligado a pagarle intereses resarcitorios calculados al doble de su tasa, sin perjuicio de sus otras responsabilidades". El mencionado artículo 49 obliga a pagar la indemnización al damnificado en el plazo de quince días desde que está en situación de ser liquidada.

8. Estos son los ejes del Proyecto de Código Civil de 1998 en materia de responsabilidad civil. Lo cual no excluye que haya adoptado otros criterios relevantes, de los cuales algunos son especialmente destacables:

- En materia de obligación de seguridad dispone: "Quien realiza una actividad, se sirve u obtiene provecho de ella, tiene a su cargo la obligación tácita de seguridad: a) Si de la actividad, o de un servicio prestado en razón de ella, puede resultar un daño a las personas que participan de la actividad o reciben el servicio, o a sus bienes. b) Si, además, puede prevenir ese daño de manera más fácil o económica que si lo hace el damnificado" (artículo 1668). "Salvo disposición legal o estipulación de partes, quien está sujeto a la obligación tácita de seguridad se libera si prueba haber actuado con diligencia, a cuyo fin debe haber adoptado las medidas de prevención razonablemente adecuadas" (artículo 1669).

- En el artículo 1600, inciso b), con criterio claramente personalista, caracteriza al daño al proyecto de vida como el que interfiere en ese proyecto, "perjudicando a la salud física o psíquica o impidiendo el pleno disfrute de la vida, así como al que causa molestias en la libertad, en la seguridad personal, en la dignidad personal, o en cualesquiera otras afecciones legítimas"; en principio, la exclusión o limitación de la responsabilidad por ese daño está prohibida (artículo 1642, inciso c)

- "En el caso de daño a intereses de incidencia colectiva corresponde prioritariamente la reposición al estado anterior al hecho generador, sin perjuicio de las demás responsabilidades. Si la reposición es total o parcialmente imposible, el responsable debe reparar el daño mediante otros bienes que satisfagan intereses de incidencia colectiva equivalentes a los afectados" (artículo 1622).
Distingue el caso fortuito del impedimento ajeno a la voluntad del deudor, que es definido como el "que, sin configurar caso fortuito, no puede ser evitado, superado, o resistido, mediante el empleo de la diligencia exigible en las circunstancias propias de la relación contractual". (artículo 1614).

- Provee reglas para la carga de la prueba del daño, de los factores de atribución y de la relación causal. Artículo 1618: "La carga de la prueba del daño corresponde a quien lo alega, salvo: a) Que la ley lo impute o lo presuma. b) Que, conforme a las reglas de la experiencia, su existencia sea presumible". Artículo 1619: "Salvo disposición legal, la carga de la prueba de los factores de atribución de la responsabilidad, así como de las circunstancias que la excluyen, corresponde a quien los alega. Si las circunstancias especiales del caso lo justifican, el tribunal puede distribuir la carga de la prueba de la culpa, o de haber actuado con diligencia, ponderando cuál de las partes está en mejor situación para aportarla" (coincide con el sentido del artículo 829, que dispone: "cuando las circunstancias especiales del caso lo justifican, el tribunal puede distribuir la carga de la prueba del pago ponderando cuál de las partes está en mejor situación para aportarla"). Artículo 1620: "La carga de la prueba de la relación causal corresponde a quien la alega, salvo: a) Que la ley la impute o la presuma. b) Que, conforme a las reglas de la experiencia, su existencia sea presumible. La carga de la prueba de la causa ajena corresponde a quien la alega".
- Establece la responsabilidad por actos involuntarios. Artículo 1652: "Son igualmente responsables, sin perjuicio de lo dispuesto en el artículo 1641 : a) Quien actúa sin discernimiento, quedando a salvo la responsabilidad del representante legal que en su caso corresponda. b) Quien causa un daño por error de hecho o de derecho, por dolo engaño, o por intimidación. El causante del dolo engaño o de la intimidación es responsable concurrente. c) Quien causa un daño mediante un acto automático o reflejo" (el mencionado artículo 1641 autoriza al tribunal "para atenuar la responsabilidad, por razones de equidad").

- Expande la legitimación para reclamar daño moral. Artículo 1689: "La persona humana damnificada directa tiene legitimación para accionar por la satisfacción de su daño extrapatrimonial. $\mathrm{Si}$ sufre gran discapacidad, o del hecho dañoso resulta su muerte, también tienen legitimación a título personal, según corresponda conforme a las circunstancias, el cónyuge, los descendientes, los ascendientes, y quienes convivían con ella recibiendo trato familiar ostensible. Los tribunales tienen atribuciones para asignar legitimación a otros sujetos, en los casos especiales en los que el hecho tiene un grado de repercusión en el reclamante que excede del ordinario, habida cuenta de su vinculación con el damnificado y las demás circunstancias".

9. Cualquier observador objetivo puede advertir el alto interés que ha despertado el Proyecto de Código Civil de 1998 en el breve tiempo corrido desde su 
presentación al Ministerio de Justicia, del cual hay varias evidencias significativas: ha sido publicado de inmediato en soporte papel, los centros académicos más respetados realizan jornadas de estudio y de análisis en todo el país $\left({ }^{* *}\right)$, y en las revistas especializadas ya aparecen los primeros comentarios de los juristas.

El mayor entusiasmo proviene de los más jóvenes, para quienes resulta intolerable que continúen siendo operativas normas que fueron adecuadas para el siglo XIX, pero que son incompatibles con la reforma constitucional de 1994, con los tratados dotados de jerarquía constitucional conforme al inciso 22 de su artículo 75 , y con las exigencias de la economía de mercado. Hiere la racionalidad que el Código de Comercio ponga todavía el acento en la responsabilidad resultante del transporte en "falúas" y en "canoas" (artículo 206); que el sistema se ocupe del agente (artículo 1151, Código Civil), quien habría viajado a caballo o en barco, y de la celebración del contrato por correspondencia (nota a los artículos 1150 a 1154, Código Civil); y que el Código Civil no mencione a las máquinas ni en el texto ni en las notas del Título en el que trata de los hechos ilícitos. El Código de Comercio alude al mensajero (artículo 215), y asume como novedad tecnológica a la correspondencia telegráfica (artículo 214; el telégrafo había sido patentado en 1840), porque lo normal

$\left({ }^{*}\right)$ El Proyecto argentino ya ha despertado interés en el plano académico internacional. En el antes mencionado Seminario se ocuparon de analizarlo los profesores italianos de la Università di Roma La Sapienza doctores Pietro Rescigno y C. Massimo Bianca; de la Università di Roma Tor Vergata, doctores Sandro Schipani y Paolo Papanti Pelletier; do Anna di Pisa, doctor Francesco Donato Busnelli; y el profesor brasileño de la Universidade de Sâo Paulo doctor Alvaro Sallaca Azevedo. En Perú será analizado en la Universidad Derecho Civil de Arequipa (4 al 6 de agosto de 1999). en el sistema era comunicarse mediante el correo (artículo 246), lo cual podía determinar que hubiera demoras notables en la trasmisión de la manifestación de la voluntad (artículo 236)...

Todo ello es congruente con la época de sanción del Código Civil: en 1869 no habían luz eléctrica, teléfonos, fonógrafos, linotipia, lapiceras fuente, automóviles propulsados a nafta o a diesel, neumáticos de caucho, películas flexibles para fotografía, cine, submarinos; no se cultivaban bacterias; no se conocía la causa de la tuberculosis ni la del tétanos, ni los rayos $\mathrm{X}$, ni los virus filtrables; no había sido fundado el psicoanálisis, ni se había descubierto la radiación del átomo de uranio.

Pero, evidentemente, las cosas han cambiado de m odo radical, primero por el auge de la sociedad industrial que los viejos Códigos no tomaron en cuenta y, en la segunda mitad de este siglo, por la irrupción de la era postindustrial o tecnológica, así como por el reciente -pero avasallador fenómeno de la globalización.

10. Argentina está en situación de tener un Código Civil moderno, a compás de los tiempos actuales, que sea -además. el primero del siglo XXI.

Ello depende, claro está, de la opinión que le merezca el Proyecto a la comunidad jurídica, y -en su caso- de la decisión política gubernamental de sancionarlo.

Revista da Faculdade de Direito da UFRGS, v. 17, 1999

\section{A Função de Satisfação na Indenização do Dano Pessoal Um elemento penal na satisfação do dano ?*}

\author{
Privatdorent Dx. Bernd-Püdigex ôexn \\ Tradução de Lélio Candiota de Campos
}

\section{Introdução}

art. 847 do BGB (Código Civil Alemão) ${ }^{* *}$ assegura uma indenização eqüitativa em dinheiro para determinados danos não patrimoniais. A este respeito, desde a decisão do Grande Senado (Gross Senat) do ano de $1955^{1}$ e de acordo com jurisprudência uniforme e a doutrina dominante, entende-se que não se trata de pretensão comum de indenização por perdas e danos, mas de uma "pretensão de na- tureza peculiar, com dupla função: propiciar ao lesado uma compensação adequada" à injustiça que sofreu e "ao mesmo tempo levar em conta que o autor do dano deve ao ofendido uma satisfação pelo que the fez". ${ }^{2}$ Quanto a isso, a revogação da segunda parte da alínea primeira do art. $847 \mathrm{em}$ $01.07 .1990^{3}$ nada mudou. O dossiê desta lei refere que "as pretensões de dano pessoal servem à compensação do dano e à satisfação da vítima". 4
Versão, ampliada e com anotaçōes, da habilitaçăo proferida em 28 de Junho 1988 na Faculdade de Direito da Eberhard-KarlsUniversität, Tübingen. Os §§ sem caracterização são os do BGB. Art. publicado no Archiv für die civilistische Praxis, vol. 191, ano 1991, pp. 247/272, Tübingen, Alemanha, traduzido pelo Prof. Lélio Candiota de Campos, com autorização do autor. O tradutor agradece a eficiente colaboração da Profa Dra Cláudia Lima Marques, que gentilmente revisou esta tradução, bem como do mestrando Christoph Fabian pela tradução das notas de rodapé.

*N.T. - Texto do art. 847 do BGB: (Dano nåo Patrimonial) No caso de lesăo do corpo ou da saúde, assim como no caso de privaçáo de liberdade, pode o lesado, também por causa do dano não patrimonial, exigir uma eqüitativa satisfação em dinheiro. A pretensão não é transmissivel e não passa para os herdeiros, salvo se tiver sido reconhecida por contrato ou tornado-se litispendente. A mesma pretensão cabe à mulher contra a qual foi cometido crime ou contravençăo contra os bons costumes, ou que foi levada, por astúcia, ameaça ou abuso de relaçăa de dependência, a consentir em coabitação extramatrimonial.

1. BGHZ 18, 149-168; sobre isto amplamente crítico Schiemann, Argumente und Prinzipien bei der Fortbildung des Schadensrechts, dargestellt an der Rechtsprechung des BGH, 1981, pp. 8-12.

2. Ementa do Supremo Tribunal Federal (BGH), BGHZ 18, 149.

3. Art. $1^{2}$ da Lei de Alteração do Bürgerliches Gesetzbuch e outras leis, de 14.3.1990; BGBI. I, 478. Cf. sobre isto Hammsen, Zur geplanten Streichung von §847 I S.2 BGB, em: VersR 1989, 1121-1123: e U.VOB, Vererblichkeit und Übertragbarkeit des Schmerzensgeldanspruchs, em: VersR 1990, 821-826.

4. Relatos dos deputados Dr. Hüsch und Stiegler de 19. Outubro 1989: BT-Dr. 11/5423.

Revista da Faculdade de Direito da UFRGS, v. 17, 1999 